\title{
A Critical Analysis of a Wireless Power Transmission (WPT) with an Improvement Method for a Non-Radiative WPT
}

\author{
Muhammad Ali ${ }^{1}$, Nurulazlina Ramli ${ }^{2}$ and Hermawan Nugroho ${ }^{3}$ \\ ${ }^{1,2}$ Centre of Advanced Electrical and Electronic Systems (CAEES), Faculty of Engineering and the Built Environment, \\ SEGi University, Kota Damansara, Malaysia \\ ${ }^{3}$ Department of Electrical and Electronic Engineering, Faculty of Engineering, University of Nottingham Malaysia.
}

\begin{tabular}{l}
\hline Article Info \\
\hline Article history: \\
Received Feb26, 2019 \\
Revised Nov 27, 2019 \\
Accepted Mar 24, 2020 \\
\hline
\end{tabular}

\section{Keyword:}

Wireless power transmission Class E power amplifier Zero voltage switching Zero derivative voltage switching

Radiative and non-radiative

\section{Corresponding Author:}

Nurulazlina Ramli,

Centre of Advanced Electrical and Electronic Systems (CAEES),

SEGi University, Malaysia,

SEGi University, Kota Damansara, 47810 Petaling Jaya, Selangor, Malaysia.

Email: azlinaramli@segi.edu.my

\begin{abstract}
This paper describes the analysis of the wireless power transmission including recent progress in non-radiative wireless power transmission (WPT) and the improvement methods. Generally, the WPT transmitter side consists of a DC supply voltage source, inverter/power amplifier, transmitter impedance matching device (IMD), source resonator and primary coil. The WPT receiver meanwhile consists of the secondary coil, device resonator, receiver IMD, rectifier and load. In order to achieve an efficient WPT, the WPT transmitter must transmit energy with minimum loss at the receiver side. This setup can be achieved by employing the power amplifier (PA). In this paper, the power amplifier in wireless power transmission for portable devices was designed. A Class E power amplifier was proposed and designed to improve the WPT transmitter side. The effects of zero voltage and zero derivative voltage switching on PA with optimization method was also discussed.
\end{abstract}

Copyright $@ 2019$ Institute of Advanced Engineering and Science. All rights reserved.

\section{INTRODUCTION}

Wireless power transfer was first invented by Nicola Tesla in the early 1890s [1]. His initial setup was based on magnetic resonance and near-field coupling of two-loop resonators. According to his theory, wireless power can be transferred using the radiative and non-radiative power transmission methods [2-3]. In radiative transmission, power is transmitted through the antenna which propagates through air or vacuum over a distance in the form of electromagnetic waves [4]. Due to its Omni-direction, the energy disperses and yields a low-efficiency energy transfer [5]. In non-radiative transmission, power transfer depends on the nearfield magnetic coupling of conductive loops. This is generally classified as short-range and mid-range nonradiative WPT [6]. For short-range, the distance between the load and source is usually only a few centimeters as they are almost attached to each other [7]. The induction motor is an example of a short-range non-radiative power transfer where the rotor part is detached inductively with the stator part. For the midrange, the transmission distance between the load and source is greater than the dimension of coil resonators (with a maximum distance of 2 meters). It is reported that with a 2-meter distance, the WPT will have $40 \%$ efficiency [8] and at the distance of 1.5 meters, the WPT will have an efficiency of approximately $80 \%$ [4].

Wireless power transfer setup consists of three major parts namely the primary (transmitter/source), the medium (air) and the receiver (load), as shown in Figure 1. The input power is fed to the source where it transmits and propagates through the air before finally delivered at the load side [9]. This distance between the primary and secondary coils is classified as the WPT system [1]. 


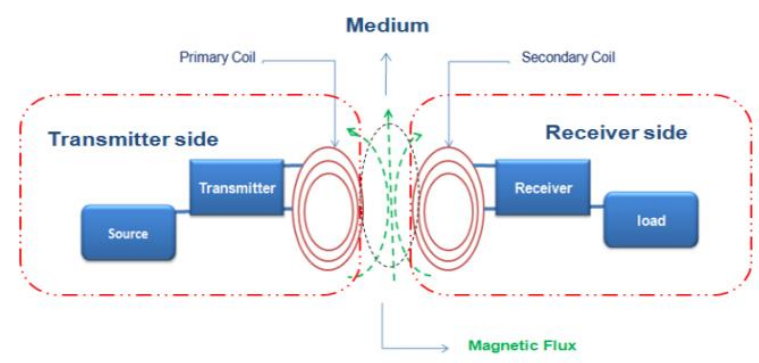

Figure 1. Basic schematic of WPT

Nowadays, WPT has become an attractive technology in the usage of portable electronics and medical implants. Generally, WPT can be divided into two main categories; radiative and non-radiative [1]. In the radiative WPT system, microwave or radio waves are used to transfer the energy. The distance between the source and the receiver can go as far as tens of kilometers. Charging a satellite with sun energy is an example of a radiative WPT system. The drawback is that it is Omni-directional in nature and thus has low efficiency. In 1896, Nicola Tesla used microwave signals to propagate energy and succeeded in transferring $1 \mathrm{GV}$ with high frequency over 25 miles to power up 200 bulbs [10]. However, its efficiency was low and with high voltage and high frequency (HF), it can cause serious damage to the human being [11]. In the 1930s, the method to convert AC current to the microwave was introduced. However, the challenge was in converting microwaves back to electricity [11]. In 1964, W.C. Brown found a way to convert microwave to electricity in a process called rectenna. In 1975, he succeeded in transferring $30 \mathrm{~kW}$ with $84 \%$ efficiency over $1.5 \mathrm{Km}$ [12]. In the 1970s to 1980 s, solar power satellite in geostationary orbit of the earth was used by NASA to transfer microwave energy from the sun to earth [11]. In 2008, the Cota system was introduced by Hatem Zeine. According to the Cota WPT system, the transmitter can deliver electrical power via microwave beams to the receiver up to 30 feet [13]. In 2011, power-cast launched a Wireless sensor system [14-16]. In the project, they used radio frequency and converted it to DC in order to supply energy to low power (microwatts and mill watts) wireless sensors.

Non-radiative WPT system uses induction and electromagnetic induction methods to transfer energy. Non-radiative WPT is further divided into two categories; short-range and mid-range. The division was based on the size of the space between the primary and secondary coils. Generally, the mid-range nonradiative WPT system has a distance between two coils larger than the radius of the coils [17]. There are two types of energy that can be transferred from primary to secondary coil namely magnetic induction and electromagnetic induction. Electromagnetic induction has strong coupling effects between two coils as compared to magnetic induction. Hence, most researchers used the electromagnetic induction method for non-radiative WPT systems [18]. In electromagnetic induction, when current flows from the transmitter to the primary coil, it produces magnetic flux. The receiver coil will receive the magnetic flux and energy will be generated as shown in Figure 1. At an early age, WPT was used only in the AC machine. WPT for DC setup was started in the 1960s for medical implants applications [19]. From the 1990s to the 2000s, there was an increase of interest in WPT research. This is because of the idea of wireless charging for consumer electronics [20]. In 2007, Kurs et al [8] introduced Witricity by transferring $60 \mathrm{~W}$ over a 2-meter distance (mid-range) with 40\% efficiency. In 2008, "Qi" (chee) commercialized the WPT technology by charging portable devices (smartphones, tab) wirelessly [21]. According to a recent report, there are currently more than 228 products that offer wireless charging [22]. There are standards for wireless charging that are constructed Wireless Power Consortium (WPC), Power Matters Alliance (PMA) and Alliance for Wireless Power (A4WP) [22-28]. In this paper, the non-radiative WPT system with a focus on consumer electronics was designed and improved.

\section{APPROACH}

According to [29], WPT will generate 12000 million dollars of revenue in 2020. The prediction is shown in Figure 2. To improve the overall efficiency of the WPT system, we found that most researchers added distant components to either the transmitter or the receiver sides of the system. As shown in Figure 3 , the inverter and power amplifiers were introduced to improve the transmitter's power efficiency. To gain optimum efficiency, the impedance between transmitter and receiver should be matching. Recent works in the Non-Radiative WPT system are discussed in Table 3. According to [30-33], power amplifiers could be applied to optimize WPT and increase the overall system efficiency. 


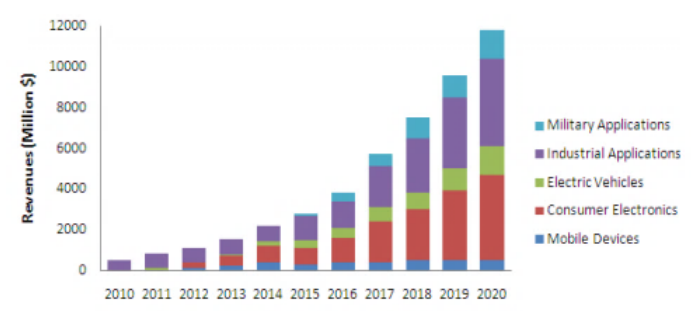

Figure 2. Predicted values of WPT technology in 2020 [29]

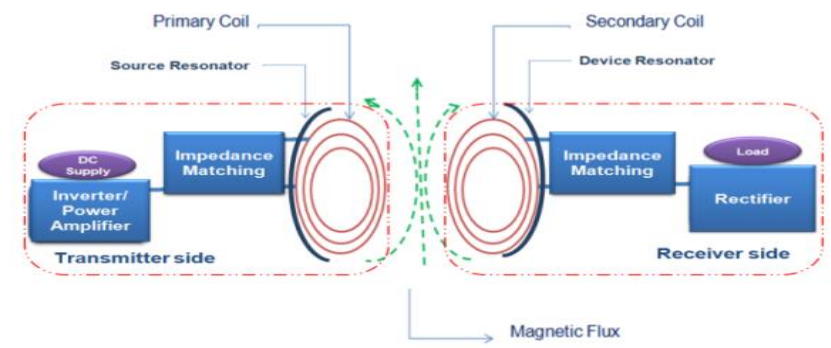

Figure 3. WPT components

Table 1. Recent works on Non-radiative WPT

\begin{tabular}{cllll}
\hline \multicolumn{5}{c}{ Recent works on Non-radiative WPT system } \\
\hline $\begin{array}{c}\text { Year } \\
\text { References }\end{array}$ & Authors/ Publications & Distance (mm) & Efficiency & Frequency \\
$2007[8]$ & Kurs et al & 2000 & $40 \%$ & $9.9 \mathrm{MHz}$ \\
$2009[34]$ & Low et al & 10 & $75.7 \%$ & $134 \mathrm{KHz}$ \\
$2010[35]$ & Yoo et al & 10 & $54.9 \%$ & $15.1 \mathrm{MHz}$ \\
$2012[36]$ & Wang et al & 05 & $74.08 \%$ & $13.56 \mathrm{MHz}$ \\
$2012[37]$ & Lee et al & 80 & $77 \%$ & $13.56 \mathrm{MHz}$ \\
$2012[30]$ & Chen et al & Nil & $73.4 \%$ & $13.56 \mathrm{MHz}$ \\
$2013[38]$ & Ahn et al & $200-310$ & $45-57 \%$ & $144 \mathrm{KHz}$ \\
$2013[39]$ & Lazaro et al & 11.35 & $82 \%$ & $100-150 \mathrm{KHz}$ \\
$2013[40]$ & Lee et al & 20 & $87 \%$ & $13.56 \mathrm{MHz}$ \\
$2014[41]$ & Ali et al & 03 & $88.11 \%$ & $22.2-22.4 \mathrm{MHz}$ \\
$2015[42]$ & Li et al & 20 & $65 \%$ & $40.68 \mathrm{MHz}$ \\
$2015[43]$ & Suzuki et al & Nil & $80.2 \%$ & $10 \mathrm{MHz}$ \\
$2015[44]$ & Ishida et al & 100 & $78 \%$ & $60 \mathrm{~Hz}$ \\
$2016[45]$ & Chung et al & 450 & $79 \%$ & $370 \mathrm{KHz}$ \\
\hline
\end{tabular}

In non-radiative systems, inductive power transmission is used to supply power to a device from source (DC supply) to load wirelessly. Researchers used the power amplifier to connect the DC supply with the primary coil [30-33]. The primary coil is mutually coupled with the secondary coil which connects to the load. The mutual inductance (MI) between the coils is proportional to the space between the primary and the secondary coils when they are in parallel and perfect alignment [46]. This 2-coil wireless power transmission is a common method in the non-radiative system [47]. Researchers proposed a new method with 4-coil power transmission to increase the power transfer efficiency with a larger coil spacing [8]. A basic schematic of a 2coil WPT is shown in Figure 4.

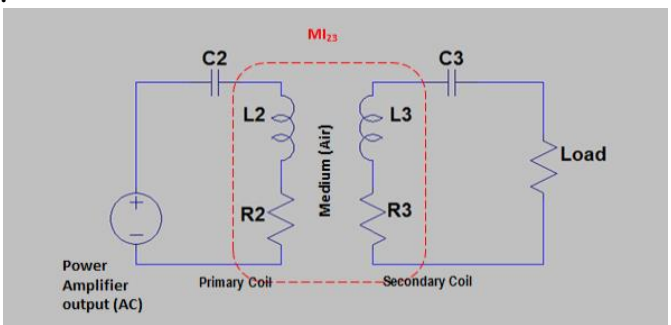

Figure 4. Basic schematic of 2-coil WPT 
As shown in Figure 4, the power amplifier will produce an AC output to the primary coil (Tx). The secondary coil (Rx) will generate energy due to the mutual inductance (MI23) between both coils. To obtain optimum efficiency, the setup must have the same tuned resonance frequency of the LC tank on both sides [48].

$f_{0}=\frac{1}{2 \pi L_{1} C_{1}}=\frac{1}{2 \pi L_{2} C_{2}}$

According to [46], Rx and Tx effects can be shown at resonance by computing reflected impedance $\left(I_{\text {ref }}\right)$. $I_{\text {xef }}=\mathbb{R}_{23}^{2} R_{2} Q_{2} Q_{3 L}$

where,

$k_{23}=\frac{M_{23}}{L_{2} L_{3}} Q_{2}=\omega_{0} \frac{L_{2}}{R_{2}}$ and $Q_{32}=\frac{Q_{3} Q_{L}}{Q_{3}+Q_{L}}$

In which, $Q_{3}=\frac{\omega_{0} L_{z}}{R_{3}}$ and $Q_{L}=\frac{R_{L}}{\omega_{0} L_{g}}$

While $Q_{L}$ represents the quality factor for load. This means that the primary loop can be simplified by replacing LC to the reflected impedance $\left(I_{\text {ref }}\right)$.

To calculate the wireless power transfer efficiency,

$\eta_{2-\text { con }}=\frac{k_{23}^{2} Q_{2} Q_{3 L}}{1+k_{23}^{2} Q_{2} Q_{3 L}} \cdot \frac{Q_{3 L}}{Q_{L}}$

As shown in Figure 5, a mutual inductance of $M_{12}$ and $M_{34}$ can be created by adding another coil.

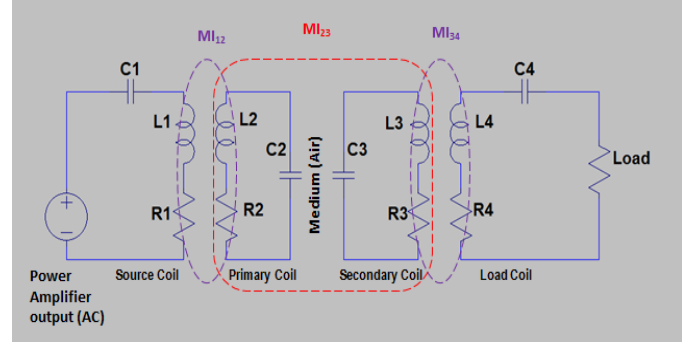

Figure 5. Basic schematic of 4-coil WPT

To calculate the power efficiency in 4-coil system,

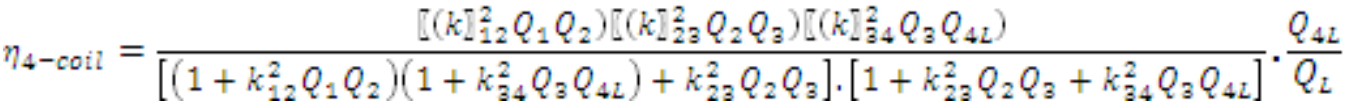

The efficiency for $\mathrm{n}^{\text {th }}$ number of coil can be obtained as,

$\eta_{\mathrm{n}-\cos }=\prod_{j=1}^{\mathrm{n}-1} \eta_{j, j+1} \cdot \frac{Q_{\mathrm{nL}}}{Q_{L}}$

As reported in previous works [7], [33], [49-56], amplifiers/rectifiers can be added in a WPT topology to improve efficiency on the transmitter side of the WPT system and thus improving overall efficiency. Chen [30], reported that switching mode power amplifiers can be used in a WPT setup as it converts DC to AC and acts as an inverter. It is reported that most Class E and Class DE switching mode power amplifiers were used as they ideally have 100\% efficiency [7], [33], [49-56]. However, the Class DE power amplifier used two transistors with the push-pull method that produces a high gate drive where it is hard to control the dead time. Therefore, it is hard to implant a Class DE power amplifier on a printed circuit board (PCB) [33] and adding two transistors will increase the cost. Taking these factors into consideration, this paper studies the Class E power amplifier which is selected to improve the efficiency of power transfer from input to the transmitter coil of the WPT system [57].

IJEEI, Vol. 8, No. 2, June 2020: 273 - 288 
Numerous analyses have recently been performed on Class E, from studies on the capacitance of drain to the source to the use of nonlinear or linear shunt capacitance. Most of the reports assumed the use of linear shunt capacitance [58]. To obtain an optimum efficiency at high frequency with low noise and zero switching loss, shunt capacitance must satisfy ZVS (zero voltage switching) or ZDS (zero derivative switchings) [59-61]. The zero-voltage switching (ZVS) condition will enable the WPT system to have high efficiency [62]. ZDS and ZVS are known generally as hard switching and soft switching respectively

In hard switching (ZDS), voltage regulators gain high switching losses due to the continuous rate of high voltage and current being applied on the regulator's integrated switch during ON and OFF conditions. The loss is increased with an increase in frequency resulting in lower efficiency. Generally, when the transistor is turned ON and OFF, voltage and current will overlap which causes hard switching losses as shown in Figure 6. However, this can be reduced by optimizing the derivative of the current and voltage in the switching waveform.

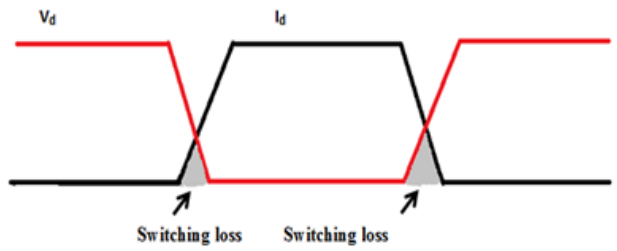

Figure 6. Switching loss in current voltage waveform

Hard switching can be further improved using a technique called soft switching (ZVS). In soft switching, the voltage will drop to zero before the transistor is turned ON or OFF. This will prevent the current waveform from overlapping with the voltage waveform. This technique minimizes the loss. The technique used to switch the transistor when the voltage reaches zero is known as zero voltage switching (ZVS). However, if the transistor is switched when the current reaches zero, it is known as zero current switchings (ZCS). Figure 7 shows the ZVS and ZCS in a current-voltage waveform.

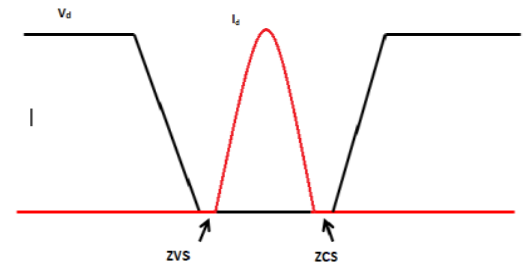

Figure 7. ZVS and ZCS current voltage waveform

Soft switching also reduces electromagnetic interference and allows for higher frequency operation [63]. In [60], a detailed analysis of the ZVS Class E power amplifier was discussed. The class E power amplifier can achieve higher efficiency in comparison with the Class B and Class C amplifiers. In Class B, the amplifier has higher power losses when the transistor is turned ON and OFF [58]. In Class E the Amplifier's efficiency can be increased by decreasing power dissipation with the desired output power. Commonly, power dissipation occurs at the transistor side. When voltage and current in a transistor are at their peaks, the overlapping of voltage and current will cause power dissipation. In Figure 8, an ideal current and voltage through the transistor are shown. However, it is a challenge to obtain a waveform as shown in Figure 8 . Achieving this waveform can reduce the power dissipation to maximize efficiency.

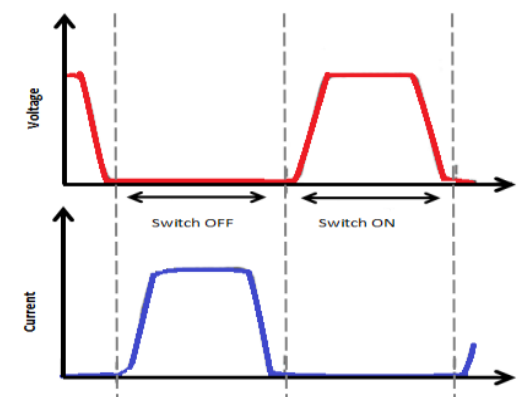

Figure 8. Ideal voltage and current waveform when the switch is $\mathrm{ON}$ and $\mathrm{OFF}$

When the transistor is $\mathrm{ON}$, the voltage in the transistor is high and it allows only voltage to flow while the current in transistor reaches almost to zero. When the transistor is OFF, the voltage turns to zero and it allowing only the current to flow. This switching affects the performance of an amplifier. Fast 
switching amplifiers can operate up to $100 \mathrm{MHz}$ frequencies. According to Sokal [60], the voltage and current waveforms will never have high voltage and high current at the same time.

Following Sokal's conditions, the following suggestions were identified to obtain high-efficiency setup;

1) Voltage and current waveforms do not exist at the same time; 2) Current waveform must reach zero before the voltage to rise. This means that when the switch is ON, the current waveform reaches its peak and decreases to zero. When the switch is turned OFF, the voltage starts to reach its peak.; 3) The voltage waveform rise section is delayed when the current reaches zero; 4) To reduce the power dissipation, the voltage and current waveforms must reach zero before the transistor is turned ON and OFF; 5) When the switch is ON, the transistor voltage is nominally zero. This means that it has no effect on the parallel shunt capacitance and will not discharge the capacitor connected in parallel. By following these suggestions, the expectation on that; 1) suggestion 1 will decrease the major power loss; 2) suggestions 2, 3,4, and 5 will reduce power dissipation when the switch is turned from ON to OFF and OFF to ON; 3) suggestions 2 and 3 are known as Zero Current Switching (ZCS) and 4) suggestions 4 and 5 are known as Zero Voltage Switching (ZVS).

In a Class E PA, the resonant circuit is included to generate bi-harmonic and poly-harmonics from the fundamental frequency. If the transmitting signal has fundamental frequency $\mathrm{f} \neg \mathrm{o}$, the resonant circuit will have a frequency of 1.5 fo followed by a filter to maximize the output power at the fundamental frequency. The resonant circuit impedance changes at its $3 \mathrm{rd}$ harmonics, 3 fo. The devices' inductive impedance is active at the 1st harmonics and capacitive reactance at other harmonics. These results voltage and current are not symmetrical which can improve the operating efficiency [58]. This method of increasing efficiency from the carrier frequency was introduced in the 1960s [64].

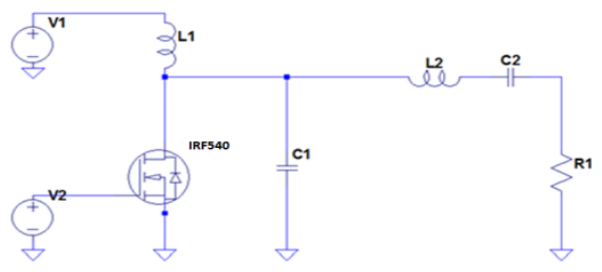

Figure 9. Basic schematic of a Class E power Amplifier

In our proposed setup, the Class $\mathrm{E}$ power amplifier consists of a switching mode transistor (IRF540), a shunt capacitor (Cs), RF choke (L1), series LC circuit resonator (L2 and C2) and load (R). A simple schematic of a Class E power amplifier is shown in Figure 9. Assuming an ideal Class E power amplifier, the voltage across the transistor can be written as;

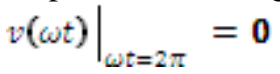

$$
\left.\frac{d v(\omega t)}{(d \omega t}\right|_{\omega t=2 \pi}=0
$$

For the current, Raab [56] reported a detailed theoretical analysis for the Class E PA where he assumed that the current is a sinusoidal,

$i_{R}(\omega t)=I_{R} \sin (\omega t+\varphi)$

When the switch is turned $\mathrm{ON}$,

$i(\omega t)=I_{0}+I_{R} \sin (\omega t+\varphi)$

At initial ON state $i(0)=0$, this can be stated as,

$I_{\sigma}=-I_{R} \sin (\varphi)$

Using trigonometric relationships [58],

$\sin \varphi=\frac{-2}{\sqrt{\pi^{2}+4}}$

and

$\cos \varphi=\frac{\pi}{\sqrt{\pi^{2}+4}}$ 
If the voltage and current are sinusoidal then there is no power loss. This means that the collector has $100 \%$ efficiency and that input dc power and output power delivered to the load are equal,

$I_{\sigma} V c c=\frac{l_{R}^{2}}{2} R$

$I_{R}^{2}=\frac{2 V_{c c l}}{R}$

$I_{R}=\sqrt{\frac{2 V c c I_{0}}{R}}$

Putting the value of $\sin \varphi$ and $\mathbb{I}_{R}$ in equation (10),

$I_{\sigma}=-\sqrt{\frac{2 V c c I_{\sigma}}{R}} \frac{-2}{\sqrt{\pi^{2}+4}}$

$l_{0}=\frac{V c c}{R} \frac{8}{\pi^{2}+4}$

Or,

$I_{0}=0.5768 \frac{V c c}{R}$

For the voltage,

$V_{R}=I_{R} R$

Putting the value of $\mathbb{I}_{\sigma}$ in the equation (13),

$0.5768 \frac{V c c}{R} V c c=\frac{I_{R}^{2}}{2} R$

$I_{R}=\sqrt{1.1536} \frac{V c c}{R}$,

Putting this value in equation (18),

$V_{R}=1.074 V c c$

Voltage across the switch consists of quadratic components calculated using Fourier series equations [58];

$V_{R}=-\frac{1}{\pi} \int_{0}^{\pi \pi} v(\omega t) \sin (\omega t+\varphi) d \omega t$

$V_{R}=\frac{l_{R}}{\pi \omega C}\left(\frac{\pi}{2} \sin 2 \varphi+2 \cos 2 \varphi\right)$

$V_{L}=-\frac{1}{\pi} \int_{0}^{\pi \pi} v(\omega t) \cos (\omega t+\varphi) d \omega t$

$V_{L}=-\frac{l_{R}}{\pi \omega C}\left(\frac{\pi}{2}+\pi \sin ^{2} \varphi+2 \sin 2 \varphi\right)$

The series inductance and shunt capacitance can be derived using equation (12) and (13);

$\frac{V_{L}}{V_{R}}=\frac{\omega L}{R}=1.1525$

$\omega C R=\frac{\omega C}{I_{R}} V_{R}=\frac{1}{5.447}$

According to Sokal, to obtain the desired output power $\left(P_{\text {out }}\right)$, the load resistance $\left(R_{l}\right)$ and supply voltage $(V c c)$ can be adjusted. Using the basic power formula $P=V I$ in equation (17);

$P_{\text {out }}=0.5768 \frac{V c c^{2}}{R}$ 
and for the load resistance,

$R_{\mathbb{I}}=0.5768 \frac{V c c^{2}}{P_{\text {out }}}$

According to Grebbennikov, the load resistance will change if the shunt capacitor is used in parallel. The formula reported by Sokal where the values of inductance and capacitance can be derived from equations (7) and (8). To obtain the value of the shunt capacitor (Cs) and its capacitance, the value of ( $\omega R$ ) must be known. If the system is ideal then $\mathrm{R}$ is equal to Rland. Using equation (18) and (27), and (26);

$\frac{\omega C}{I_{R}} V_{R}=\omega C R=\frac{1}{5.447}$

Or,

$C_{s}=\frac{0.1836}{\omega R}$

$\frac{V_{L}}{V_{R}}=\frac{\omega L}{R}=1.1525$

Or,

$L_{s}=1.1525 \frac{R}{\omega}$

For the series resonator $(L C), \omega=\frac{1}{\sqrt{L C}}$. It can be further simplified in equation (34),

$L C=\frac{1}{\omega^{2}}$

To obtain individual values of $(L)$ and $(C)$ in the $L C$ series circuit, equation (34) was further elaborated by Grebennikov [65]. In equation (36), a quality factor $(Q)$ is added which explains the quality factor of the load resistor. The value of $\mathrm{Q}$ is an assumption and must be greater or equal to 1.7879 [60].

$L_{0}=\frac{1}{\omega^{2} C_{0}}$

$C_{0}=\frac{1}{\omega Q R}$

Multiple factors should be taken into consideration while designing a wireless power transmission setup such as size, weight, and cost. The size of the setup depends on the primary and secondary coils of the setup. Large coils should be used to strengthen the coupling effects between the two coils if we are using $\mathrm{KHz}$ frequency $(400 \mathrm{KHz})$. But if we use the high frequency in $\mathrm{MHz}$, a strong coupling effect can be achieved with a smaller coil size resulting in a lighter weight and a cheaper cost. Taking this and ISM band (industrial, scientific and medical) standards into consideration, $1 \mathrm{MHz}$ was used in this paper [66].

The portable devices generally have supply voltages of $5 \mathrm{~V}, 9 \mathrm{~V}$, and $12 \mathrm{~V}$. Normally, the $5 \mathrm{~V}$ is used for power banks, $9 \mathrm{~V}$ is used in wireless charging pads and $12 \mathrm{~V}$ is used to charge toys such as drones. Using the previous equations, the parameters set up for the amplifier was calculated. Chen et al [30] and Srimuang et. al [67] used $25 \mathrm{~V}$ and $32 \mathrm{~V}$ drain voltages respectively in their previous works. However, that $32 \mathrm{~V}$ and $25 \mathrm{~V}$ DC were not practical as most of the smartphones today use $5 \mathrm{~V}$ with $2 \mathrm{~A}(10 \mathrm{~W})$ for charging of the battery. Portable power banks available in markets has similar output configuration (10W) [68]. In the simulation and experiment, besides $5 \mathrm{~V}$, the supply voltage of $9 \mathrm{~V}$ and $12 \mathrm{~V}$ also has been used to simulate the practicality of the designed power amplifiers.

\section{RESULT AND ANALYSIS}

In this work, the Class E power amplifier has been designed and simulated with LTsim software. The setup was then tested in experiments. A few simulations were carried out in this paper. In the first simulation, the $5 \mathrm{~V}$ drain voltage with $5 \mathrm{~V}$ and $6 \mathrm{~V}$ gate voltage has been used as shown in Table 4 . Increasing the gate voltage can increase the efficiency of the designed setup. In Table 5, the drain voltage is constant at $5 \mathrm{~V}$ and the gate voltage has been varied from $4 \mathrm{~V}$ to $6 \mathrm{~V}$.

IJEEI, Vol. 8, No. 2, June 2020: 273 - 288 
Table 4. Efficiency with $5 \mathrm{~V}$ and $6 \mathrm{~V}$ gate voltage

\begin{tabular}{ccccc}
\hline $\begin{array}{c}\text { Drain } \\
\text { voltage }(\mathbf{V})\end{array}$ & $\begin{array}{c}\text { Gate voltage } \\
(\mathbf{V})\end{array}$ & $\begin{array}{c}\text { Power input } \\
(\mathbf{m W})\end{array}$ & $\begin{array}{c}\text { Power output } \\
(\mathbf{m W})\end{array}$ & $\begin{array}{c}\text { Efficiency } \\
(\boldsymbol{\%})\end{array}$ \\
\hline 1 & 5 & 25.163 & 21.028 & 83.57 \\
2 & 5 & 105.31 & 89.065 & 84.574 \\
3 & 5 & 238.71 & 203.41 & 85.21 \\
4 & 5 & 437.88 & 373.71 & 85.35 \\
5 & 5 & 704.35 & 602.72 & 85.57 \\
6 & 5 & 1038 & 892.87 & 86.02 \\
7 & 5 & 1435.9 & 1241.8 & 86.48 \\
1 & 6 & 33.524 & 29.197 & 87.09 \\
2 & 6 & 139.41 & 122.64 & 87.97 \\
3 & 6 & 318.55 & 280.49 & 88.05 \\
4 & 6 & 580.14 & 514.36 & 88.66 \\
5 & 6 & 918.34 & 825.87 & 89.93 \\
6 & 6 & 1346.7 & 1215.3 & 90.24 \\
7 & 6 & 1857.7 & 1681 & 90.49 \\
\hline
\end{tabular}

Table 5. Efficiency with constant drain voltage

\begin{tabular}{ccccc}
\hline $\begin{array}{c}\text { Drain voltage } \\
(\mathbf{V})\end{array}$ & $\begin{array}{c}\text { Gate Voltage } \\
(\mathbf{V})\end{array}$ & $\begin{array}{c}\text { Power input } \\
(\mathbf{m W})\end{array}$ & $\begin{array}{c}\text { Power output } \\
(\mathbf{m W})\end{array}$ & Efficiency (\%) \\
\hline 5 & 4 & 190.43 & 77.466 & 40.68 \\
5 & 5 & 704.35 & 602.72 & 85.57 \\
5 & 6 & 926.62 & 825.87 & 89.93 \\
\hline
\end{tabular}

Table 6. System Setup for $5 \mathrm{~V}$ drain voltage

\begin{tabular}{lllc}
\hline Parameters & $\begin{array}{l}\text { Calculated } \\
\text { values }\end{array}$ & $\begin{array}{l}\text { Simulation with } \\
\text { calculated } \\
\text { values }\end{array}$ & $\begin{array}{c}\text { Simulation with parameters } \\
\text { available in market }\end{array}$ \\
\hline Drain Voltage & $5 \mathrm{~V}$ & $5 \mathrm{~V}$ & $5 \mathrm{~V}$ \\
Gate voltage & $6 \mathrm{~V}$ & $6 \mathrm{~V}$ & $6 \mathrm{~V}$ \\
$\mathrm{~L} 1$ & $2.98 \mathrm{uH}$ & $3 \mathrm{uH}$ & $3.3 \mathrm{uH}$ \\
$\mathrm{C} 1$ & $2.17 \mathrm{nF}$ & $2 \mathrm{nF}$ & $2.2 \mathrm{nF}$ \\
$\mathrm{L} 2$ & $11.345 \mathrm{uH}$ & $11 \mathrm{uH}$ & $12 \mathrm{uH}$ \\
$\mathrm{C} 2$ & $1.864 \mathrm{uF}$ & $2 \mathrm{nF}$ & $2.2 \mathrm{nF}$ \\
R1 & $14.77 \Omega$ & $15 \Omega$ & $15 \Omega$ \\
Pout & $1 \mathrm{~W}$ & $825 \mathrm{~mW}$ & $823 \mathrm{~mW}$ \\
Frequency & $1 \mathrm{MHz}$ & $1 \mathrm{MHz}$ & $1 \mathrm{MHz}$ \\
Efficiency & - & $89.93 \%$ & $89.67 \%$ \\
\hline
\end{tabular}

Figure 10 shows the simulation results of the drain and gate voltage wavelength while supplying $5 \mathrm{~V}$ drain voltage and $6 \mathrm{~V}$ gate voltage. Figure 11 shows the voltage and current waveform at the load resistance.

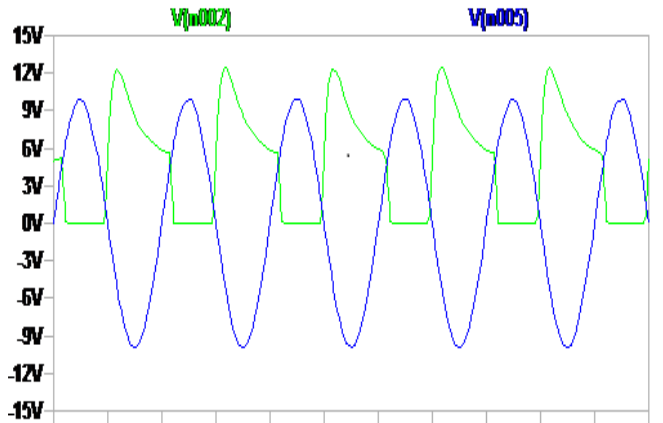

Figure 10. Drain voltage $\mathrm{V}(\mathrm{n} 002)$ and gate voltage $\mathrm{V}(\mathrm{n} 005)$ when drain voltage $\mathrm{V} 1$ is $5 \mathrm{~V}$ 


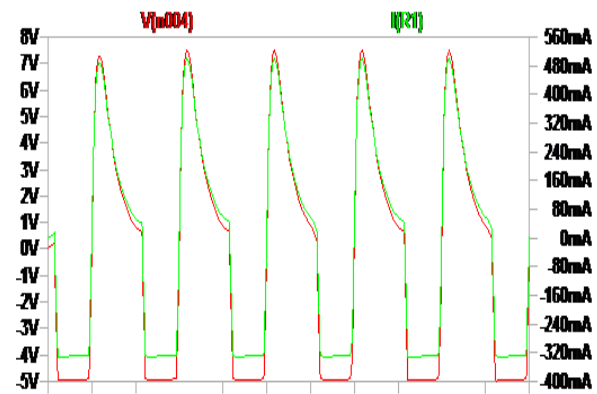

Figure 11. Voltage and current waveforms at load resistor R1 when V1 is $5 \mathrm{~V}$. V(n004) waveform shows the voltage supplied and $\mathrm{I}(\mathrm{R} 1)$ is current wavelength

Experiments were then conducted with the actual ICs (refer to Figure 16). Table 7 shows the comparison between the actual and the simulated results. It showed that the actual efficiency for $5 \mathrm{~V}$ drain voltage and $6 \mathrm{~V}$ gate voltage was around $80 \%$.

Table 7. Comparison between simulated and actual with $5 \mathrm{~V}$ drain voltage

\begin{tabular}{ccccccc}
\hline Vdd & \multicolumn{3}{c}{ Simulation } & \multicolumn{3}{c}{ Actual } \\
\cline { 2 - 7 } & Pin & Pout & Efficiency & Pin & Pout & Efficiency \\
\hline 5 & 0.926 & 0.825 & $89.93 \%$ & 1.034 & 0.823 & $79.67 \%$ \\
6 & 1.077 & 0.973 & $90.34 \%$ & 1.389 & 1.115 & $80.25 \%$ \\
7 & 1.241 & 1.128 & $90.85 \%$ & 1.892 & 1.523 & $80.47 \%$ \\
\hline
\end{tabular}

In the next simulation and experiment, another Class $\mathrm{E}$ power amplifier for $9 \mathrm{~V}$ drain voltage was designed. Table 8 shows the calculated parameters with $9 \mathrm{~V}$ drain supply voltage and $6 \mathrm{~V}$ gate voltage. With this setting ( $9 \mathrm{~V}$ drain voltage and $6 \mathrm{~V}$ gate voltage), $91.32 \%$ efficiency was achieved. Since some of the calculated parameters could not be found in the market, the simulation was performed with parameters available in the market. In this setting, the efficiency was slightly lower (90.93\%).

Table 8. System setup for $9 \mathrm{~V}$ drain voltage

\begin{tabular}{lccc}
\hline Parameters & Calculated values & $\begin{array}{c}\text { Simulation with } \\
\text { calculated values }\end{array}$ & $\begin{array}{c}\text { Simulation with parameters } \\
\text { available in market }\end{array}$ \\
\hline Drain Voltage & $9 \mathrm{~V}$ & $9 \mathrm{~V}$ & $9 \mathrm{~V}$ \\
Gate voltage & $6 \mathrm{~V}$ & $6 \mathrm{~V}$ & $6 \mathrm{~V}$ \\
$\mathrm{~L} 1$ & $2.756 \mathrm{uH}$ & $2.7 \mathrm{uH}$ & $2.7 \mathrm{uH}$ \\
$\mathrm{C} 1$ & $1.9479 \mathrm{nF}$ & $2 \mathrm{nF}$ & $2.2 \mathrm{nF}$ \\
$\mathrm{L} 2$ & $2.389 \mathrm{uH}$ & $2.4 \mathrm{uH}$ & $2.2 \mathrm{uH}$ \\
$\mathrm{C} 2$ & $10.623 \mathrm{nF}$ & $10.6 \mathrm{nF}$ & $10.2 \mathrm{nF}$ \\
$\mathrm{R} 1$ & $15 \Omega$ & $15 \Omega$ & $15 \Omega$ \\
Pout & $2.5 \mathrm{~W}$ & $2.4039 \mathrm{~W}$ & 2.3925 \\
Frequency & $1 \mathrm{MHz}$ & $1 \mathrm{MHz}$ & $1 \mathrm{MHz}$ \\
Efficiency & - & $91.32 \%$ & $90.93 \%$ \\
\hline
\end{tabular}

The simulation results are shown in Figure 12 which presents the drain and gate voltage wavelength while supplying $9 \mathrm{~V}$ drain voltage and $6 \mathrm{~V}$ gate voltage. Figure 13 shows the voltage and current waveform at the load resistance.

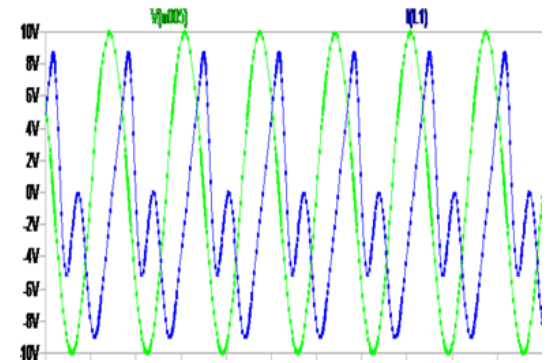

Figure 12. Drain voltage $\mathrm{V}(\mathrm{n} 002)$ and gate voltage $\mathrm{I}(\mathrm{L} 1)$ wavelength when drain voltage $\mathrm{V} 1$ is $9 \mathrm{~V}$ 


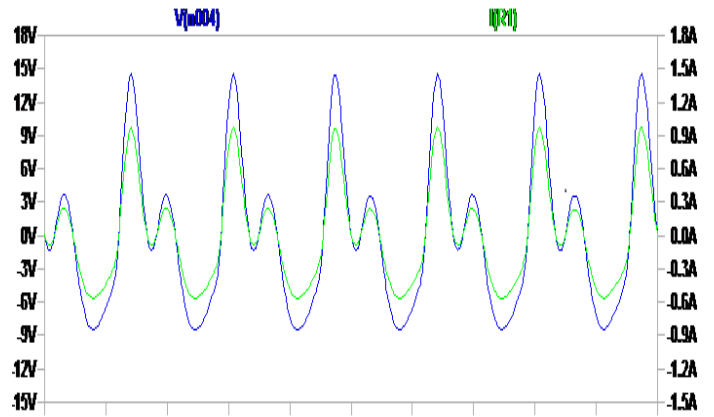

Figure 13. Voltage and current waveforms at load resistor R1 when V1 is 9V. V (n004) waveform shows the voltage supplied and $\mathrm{I}(\mathrm{R} 1)$ is current wavelength

In Table 9, the drain voltage is constant at $9 \mathrm{~V}$ and the gate voltage has been changed from $4 \mathrm{~V}$ to $6 \mathrm{~V}$. The highest efficiency was achieved at gate voltage $6 \mathrm{~V}(91.32 \%)$. Experiments were then conducted with the actual ICs (refer to Figure 16). Table 10 shows a comparison between the actual and the simulated result. It is shown that the actual efficiency for $9 \mathrm{~V}$ drain voltage where the $9 \mathrm{~V}$ gate voltage is around $79 \%$.

Table 9. System efficiency with $9 \mathrm{~V}$ drain voltage

\begin{tabular}{ccccc}
\hline Drain voltage (V) & Gate Voltage (V) & Power input (W) & Power output (W) & Efficiency (\%) \\
\hline 9 & 4 & $414.07 \mathrm{~mW}$ & $178.66 \mathrm{~mW}$ & 43.15 \\
9 & 5 & 2.1323 & 1.8136 & 85.05 \\
9 & 6 & 2.6325 & 2.4039 & 91.32 \\
\hline
\end{tabular}

Table 10. Comparison between simulated and actual

\begin{tabular}{ccccccc}
\hline \multirow{2}{*}{ Vdd } & \multicolumn{3}{c}{ Simulation } & \multicolumn{3}{c}{ Actual } \\
\cline { 2 - 6 } & Pin & Pout & Efficiency & Pin & Pout & Efficiency \\
\hline 9 & 2.6309 & 2.3925 & $90.93 \%$ & 2.016 & 1.5936 & $79.04 \%$ \\
10 & 3.3061 & 3.0126 & $91.12 \%$ & 2.41 & 1.9201 & $79.67 \%$ \\
11 & 4.0385 & 3.6840 & $91.22 \%$ & 2.816 & 2.19657 & $78.00 \%$ \\
\hline
\end{tabular}

In the last simulation and experiment, another Class $\mathrm{E}$ power amplifier for $12 \mathrm{~V}$ drain voltage was designed. Table 11 shows the calculated parameters using the $12 \mathrm{~V}$ drain supply voltage and $6 \mathrm{~V}$ gate voltage. With this setting ( $9 \mathrm{~V}$ drain voltage and $6 \mathrm{~V}$ gate voltage), $87.75 \%$ efficiency was achieved. Since some of the calculated parameters could not be found in the market, the simulation was performed with parameters available in the market. In this setting, the efficiency was slightly lower $(84.18 \%)$.

Table 11. System Setup for $12 \mathrm{~V}$ drain voltage

\begin{tabular}{lccc}
\hline Parameters & Calculated values & $\begin{array}{c}\text { Simulation with calculated } \\
\text { values }\end{array}$ & $\begin{array}{c}\text { Simulation with parameters } \\
\text { available in market }\end{array}$ \\
\hline Drain Voltage & $12 \mathrm{~V}$ & $12 \mathrm{~V}$ & $12 \mathrm{~V}$ \\
Gate voltage & $6 \mathrm{~V}$ & $6 \mathrm{~V}$ & $6 \mathrm{~V}$ \\
$\mathrm{~L} 1$ & $1.5241 \mathrm{uH}$ & $1.5 \mathrm{uH}$ & $1.5 \mathrm{uH}$ \\
$\mathrm{C} 1$ & $3.5167 \mathrm{nF}$ & $3.5 \mathrm{nF}$ & $3.3 \mathrm{nF}$ \\
$\mathrm{L} 2$ & $1.3224 \mathrm{uH}$ & $1.3 \mathrm{uH}$ & $1.2 \mathrm{uH}$ \\
$\mathrm{C} 2$ & $19.1555 \mathrm{nF}$ & $19 \mathrm{nF}$ & $18 \mathrm{nF}$ \\
R1 & $8.3088 \Omega$ & $8 \Omega$ & $8.2 \Omega$ \\
Pout & $8 \mathrm{~W}$ & $7.545 \mathrm{~W}$ & 6.6425 \\
Frequency & $1 \mathrm{MHz}$ & $1 \mathrm{MHz}$ & $1 \mathrm{MHz}$ \\
Efficiency & - & $87.75 \%$ & $84.18 \%$ \\
\hline
\end{tabular}


Figure 14 shows the drain and gate voltage wavelength while supplying $12 \mathrm{~V}$ drain voltage and $6 \mathrm{~V}$ gate voltage. Figure 15 shows the voltage and current waveform at the load resistance. In Table 12, the drain voltage is constant at $12 \mathrm{~V}$ and the gate voltage has been varied from $4 \mathrm{~V}$ to $6 \mathrm{~V}$. The highest efficiency was achieved at gate voltage $6 \mathrm{~V}(87.75 \%)$.

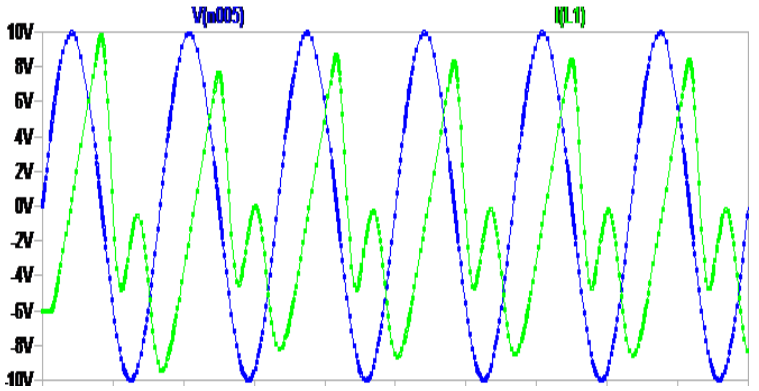

Figure 14. Drain voltage V(n002) and gate voltage $\mathrm{I}(\mathrm{L} 1)$ wavelength when drain voltage V1 is $12 \mathrm{~V}$

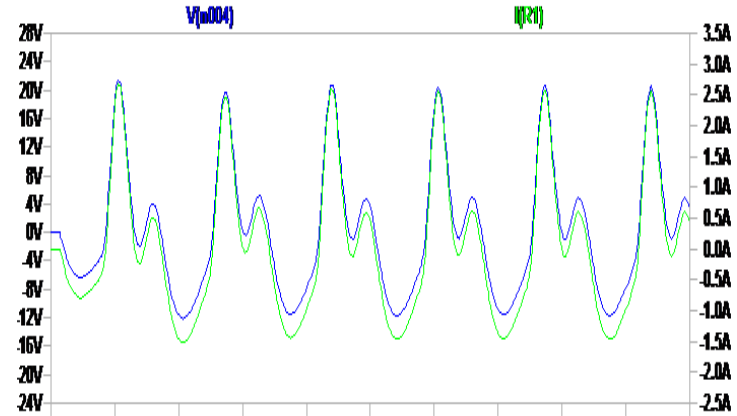

Figure 15. Voltage and current waveforms at load resistor R1 when V1 is $12 \mathrm{~V}$. V (n004) waveform shows the voltage supplied and $\mathrm{I}(\mathrm{R} 1)$ is current wavelength

Table 12. System efficiency with $12 \mathrm{~V}$ drain voltage

\begin{tabular}{ccccc}
\hline Drain voltage $(\mathbf{V})$ & Gate Voltage $(\mathbf{V})$ & Power input $(\mathbf{W})$ & Power output $(\mathbf{W})$ & Efficiency (\%) \\
\hline 12 & 4 & 1.0435 & $588.45 \mathrm{~mW}$ & 56.39 \\
12 & 5 & 5.8196 & 4.6046 & 79.12 \\
12 & 6 & 8.5986 & 7.545 & 87.75
\end{tabular}

Experiments were then conducted with the actual ICs (refer to Figure 16). Table 13 shows a comparison between the actual and the simulated result. It is shown that the actual efficiency for $12 \mathrm{~V}$ drain voltage and $12 \mathrm{~V}$ gate voltage is around $75 \%$.

Table 13. Comparison between simulated and actual

\begin{tabular}{ccccccc}
\hline Vdd & \multicolumn{3}{c}{ Simulation } & & \multicolumn{3}{c}{ Actual } \\
& Pin & Pout & Efficiency & Pin & Pout & Efficiency \\
& 7.8904 & 6.6425 & $84.18 \%$ & 4.992 & 3.759 & $75.30 \%$ \\
13 & 9.2194 & 7.7662 & $84.23 \%$ & 5.525 & 4.1697 & $75.46 \%$ \\
14 & 10.644 & 8.9733 & $84.30 \%$ & 6.006 & 4.4982 & $74.89 \%$ \\
\hline
\end{tabular}

$1 \mathrm{MHz}$ frequency with IRF540-N switch was used for all the actual experiments. This result shows that with the $5 \mathrm{~V}, 9 \mathrm{~V}, 12 \mathrm{~V}$ drain voltages, the system can achieve between $75 \%$ to $80 \%$ efficiency indicating a promising result. From the experiments, when the supplying drain voltage is above $12 \mathrm{~V}$, it will heat up the switch. This is due to a high switching loss. Figure 16 (a, b, c and d) shows the actual design of the Class E power amplifier. 


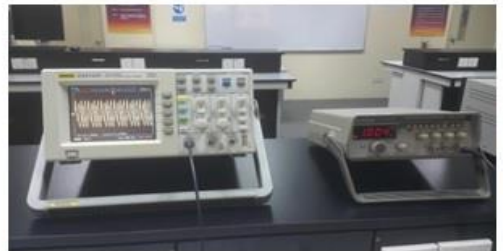

(a)

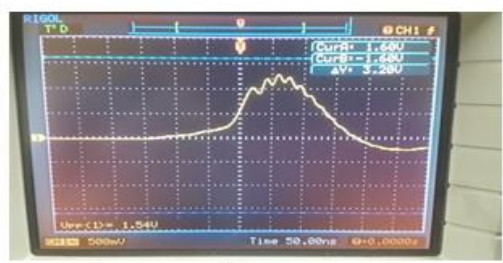

(c)

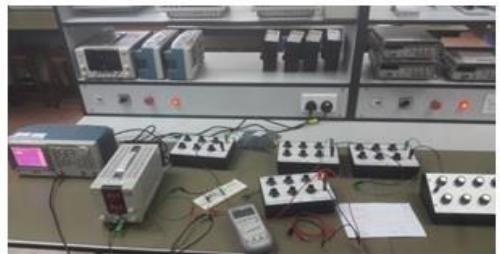

(b)

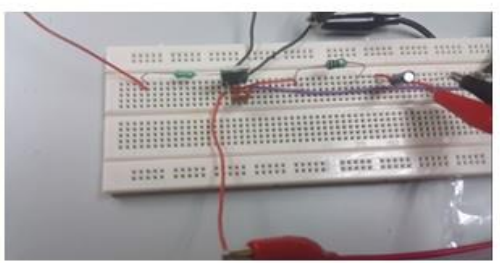

(d)

Figure 16. Designed Class E PA

The efficiency of the power amplifier will affect the overall efficiency of the end-to-end WPT system efficiency. An efficient power amplifier will improve the efficiency of the WPT system. In this paper, the Class E power amplifier has been designed and tested for $5 \mathrm{~V}, 9 \mathrm{~V}$ and $12 \mathrm{~V}$ settings which achieved very good efficiencies. A further extension of the current design will improve the complete setup of the wireless power transmission system for portable devices such as mobile handsets, wireless chargers, and drones.

\section{CONCLUSION}

Wireless power transfer (WPT) is currently one of the rising issues in this industry. In this paper, a non-radiative WPT system with the focus on consumer electronics was designed, improved and proposed to implement the Class E power amplifier on the transmitter side of the WPT system. An effective power amplifier will improve the overall efficiency of the WPT system. The system is designed and simulated based on three voltage settings of the current consumer electronics $(5 \mathrm{~V}, 9 \mathrm{~V}$, and $12 \mathrm{~V})$. The parameters of Class $\mathrm{E}$ were computed analytically using the formula generated from the literature review. The parameters were then simulated using the LTspice simulation software before the actual settings were built. Results showed a high efficiency $(75 \%-80 \%)$ indicating a very promising result.

\section{ACKNOWLEDGEMENTS}

The authors would like to thank the Centre of Advanced Electrical and Electronic Systems (CAEES), Faculty of Engineering and the Built Environment, SEGi University and Institute of Graduate Studies, SEGi University for sponsoring this work and providing insight and expertise that greatly assisted our research. The thanks also had been given to the Department of Electrical and Electronic Engineering, Faculty of Engineering, University of Nottingham, Malaysia for support in obtaining the information and expertise.

\section{REFERENCES}

[1] S. Y. R. Hui, W. Zhong, and C. K. Lee, "A Critical Review of Recent Progress in Mid-Range Wireless Power Transfer," IEEE Trans. Power Electron., vol. 29, no. 9, pp. 4500-4511, 2014.

[2] M. Liu, M. Fu, and C. Ma, "A compact class E rectifier for megahertz wireless power transfer," IEEE PELS Work. Emerg. Technol. Wirel. Power, pp. 1-5, 2015.

[3] A. Karalis, J. D. Joannopoulos, and M. Solja, "Efficient wireless non-radiative mid-range energy transfer I . Introduction," pp. 1-19.

[4] J. Choi and C. Seo, "High-efficiency wireless energy transmission using magnetic resonance based on metamaterial with relative permeability equal to- 1," Prog. Electromagn. Res., vol. 106, no. May, pp. 33-47, 2010.

[5] Z. N. Low, "High Efficiency Loosely Coupled Wireless Power Transfer System via Magnetic Induction," University of Florida, 2009.

[6] J. Dai, S. Member, and D. C. Ludois, "A Survey of Wireless Power Transfer and a Critical Comparison of Inductive and Capacitive Coupling for Small Gap Applications," IEEE Trans. Power Electron., vol. 30, no. 11, pp. 6017-6029, 2015.

[7] T. Nagashima, X. Wei, and H. Sekiya, "Analytical design procedure for resonant inductively coupled wireless power transfer system with class-E inverter and class-DE rectifier," 2014 IEEE Asia Pacific Conf. Circuits Syst., pp. 288-291, 2014.

[8] A. Kurs, A. Karalis, R. Moffatt, J. D. Joannopoulos, P. Fisher, and M. Soljacic, "Wireless power transfer via 
strongly coupled magnetic resonances.," Science, vol. 317, no. 5834, pp. 83-86, 2007.

[9] M. Kurs, A., Karalis, A., Moffatt, R., Joannopoulos, J. D., Fisher, P., \& Soljačić, "Wireless power transfer via strongly coupled magnetic resonances," Science (80-. )., vol. 317, no. American Association for the Advancement of Science, pp. 83--86, 2007.

[10] N. Tesla, "TESLA PATENT 1,119,732 APPARATUS FOR TRANSMITTING ELECTRICAL ENERGY.," 1914.

[11] X. Lu, P. Wang, D. Niyato, D. I. Kim, Z. Han, and C. Engineering, "Wireless Charging Technologies: Fundamentals, Standards, and Network Applications," no. c, pp. 1-41, 2015.

[12] B. Strassner and and K. Chang, "Microwave Power Transmission: Historical Milestones and System Components," Proc. IEEE, vol. 101, pp. 1379-1396, 2013.

[13] “ossiainc." [Online]. Available: http://www.ossiainc.com.

[14] "powercastco." [Online]. Available: www.powercastco.com.

[15] M. Cheney, Tesla: Man Out of Time. 1981.

[16] J. O. McSpadden and J. C. Mankins, "Space solar power programs and microwave wireless power transmission technology," IEEE Microw. Mag., vol. 3, no. 4, pp. 46-57, 2002.

[17] S. Y. R. Hui, W. X. Zhong, and C. K. Lee, "A Critical Review of Recent Progress in Mid-Range Wireless Power Transfer," IEEE Trans. Power Electron., vol. PP, no. 99, pp. 1-38, 2013.

[18] J. H. Shoki ; Corp. R\&D Center, Toshiba Corp., Kawasaki, "Issues and initiatives for practical use of wireless power transmission technologies in Japan," Microw. Work. Ser. Innov. Wirel. Power Transm. Technol. Syst. Appl. (IMWS), 2011 IEEE MTT-S Int., no. IEEE, pp. 87-90, 2011.

[19] G. A. C. And and J. T. Boys, "Inductive Power Transfer," Proc. IEEE, vol. 101, pp. 1276-1289, 2013.

[20] A. V. Timm, G. ShearerJohn, and R. ShearerJohn, "Method and apparatus for a wireless power supply," U.S. Pat. number 7,027,311, 2006.

[21] L. Shi et al., "Wireless Power Hotspot that Charges All of Your Devices," 2016.

[22] "wirelesspowerconsortium." [Online]. Available: www.wirelesspowerconsortium.com.

[23] A. Kumar and B. Gowda, "WiTricity:Wireless Power Transfer By Non-radiative Method," Ijettjournal.Org, vol. 11, no. 6, pp. 290-295, 2014.

[24] J. Jadidian and D. Katabi, "Magnetic MIMO : How To Charge Your Phone in Your Pocket," pp. 495-506, 2016.

[25] "airfuel." [Online]. Available: http://www.airfuel.org/.

[26] "LIMITS OF HUMAN EXPOSURE TO RADIOFREQUENCY ELECTROMAGNETIC ENERGY IN THE FREQUENCY RANGE FROM 3 KHZ TO 300 GHZ,” 2015.

[27] L. Xie, Lou, Y. Shi, Andwenjing, and ; Y. T. H., "Wireless power transfer and applications to sensor networks," IEEE Wirel. Commun., vol. 20, no. 4, pp. 140-145, 2013.

[28] M. Kesler, "Highly Resonant Wireless Power Transfer: Safe, Efficient, and over Distance," WiTricity Corp, 2013.

[29] "Wireless Power Transmission: Patent Landscape Analysis."

[30] W. Chen et al., "A 25 .6 W 13.56 MHz Wireless Power Transfer System with a 94 \% Efficiency GaN Class-E Power Amplifier," IEEE, pp. 25-27, 2012.

[31] N. Keskin and H. Liu, “Complementary Class-E Amplifier for Wireless Power Transfer,” pp. 2235-2240, 2015.

[32] H. Hwang, S. Yang, and C. Seo, "High Gain and High PAE Power Amplifier by Employing Adaptive Bias Control Circuit for Resonant WPT," vol. 2, pp. 496-498, 2012.

[33] R. J. Calder, S.-H. Lee, and R. D. Lorenz, "Efficient, MHz frequency, resonant converter for sub-meter $(30 \mathrm{~cm})$ distance wireless power transfer," Energy Convers. Congr. Expo., no. 30 cm, pp. 1917-1924, 2013.

[34] Z. N. Low, R. A. Chinga, R. Tseng, and J. Lin, "Design and Test of a High-Power High-Efficiency Loosely Coupled Planar Wireless Power Transfer System," IEEE Trans. Ind. Electron., vol. 56, pp. 1801-1812, 2009.

[35] J. Yoo, L. Yan, S. Lee, Y. Kim, and H. J. Yoo, "A $5.2 \mathrm{~mW}$ Self-Configured Wearable Body Sensor Network Controller and a $12 \mathrm{lmu}$ W Wirelessly Powered Sensor for a Continuous Health Monitoring System," IEEE J. Solid-State Circuits, vol. 45, pp. 178-188, 2010.

[36] Wang, Huang, Zhu.Y, H. G. Qiyu, X. Zhu, and T. Mo, "Enabling multi-angle wireless power transmission via magnetic resonant coupling," Comput. Converg. Technol. (ICCCT), 2012 7th Int. Conf., pp. 1395-1400, 2012.

[37] H. M. Lee and M. Ghovanloo, "An Adaptive Reconfigurable Active Voltage Doubler/Rectifier for ExtendedRange Inductive Power Transmission," IEEE Trans. Circuits Syst. II Express Briefs, vol. 59, no. 8, pp. 481-485, 2012.

[38] D. Ahn and S. Hong, "Effect of Coupling Between Multiple Transmitters or Multiple Receivers on Wireless Power Transfer," IEEE Trans. Ind. Electron., vol. 60, no. 7, pp. 2602-2613, 2013.

[39] O. Lazaro and G. A. Rincón-Mora, "180-nm CMOS Wideband Capacitor-Free Inductively Coupled Power Receiver and Charger,” IEEE J. Solid-State Circuits, vol. 48, no. 11, pp. 2839-2849, 2013.

[40] S. Y. Lee, J. H. Hong, C. H. Hsieh, M. C. Liang, and J. Y. Kung, “A Low-Power 13.56 MHz RF Front-End Circuit for Implantable Biomedical Devices,” IEEE Trans. Biomed. Circuits Syst., vol. 7, no. 3, pp. 256-265, 2013.

[41] M. T. Ali, A. Anwar, U. Tayyab, Y. Iqbal, T. Tauqeer, and U. Nasir, "Design of high efficiency wireless power transmission system at low resonant frequency," Power Electron. Motion Control Conf. Expo. (PEMC), 2014 16th Int., pp. 1128-1133, 2014.

[42] X. Li, C. Y. Tsui, and W. H. Ki, "Power Management Analysis of Inductively-Powered Implants with 1X/2X Reconfigurable Rectifier," IEEE Trans. Circuits Syst. I Regul. Pap., vol. 62, no. 3, pp. 617-624, 2015. 
[43] S. Suzuki and T. Shimizu, "A high-frequency current-output-type inverter aimed for wireless power transmission system," 2015 IEEE Energy Convers. Congr. Expo. (ECCE, pp. 5732-5740, 2015.

[44] H. Ishida and H. Furukawa, "Wireless Power Transmission Through Concrete Using Circuits Resonating at Utility Frequency of 60 Hz," IEEE Trans. Power Electron., vol. 30, no. 3, pp. 1220-1229, 2015.

[45] H. Y. D. Chung and C. Y. Lee, "Design Considerations of Superconducting Wireless Power Transfer for Electric Vehicle at Different Inserted Resonators," IEEE Trans. Appl. Supercond., vol. 26, no. 4.

[46] M. Kiani, U. M. Jow, and M. Ghovanloo, "Design and Optimization of a 3-Coil Inductive Link for Efficient Wireless Power Transmission,” IEEE Trans. Biomed. Circuits Syst., vol. 5, no. 6, pp. 579-591, 2011.

[47] U. Jow and M. Ghovanloo, "Design and optimization of printed spiral coils for efficient transcutaneous inductive power transmission," IEEE Trans. Biomed. Cir. Syst., pp. 193-202, 2007.

[48] M. W. Baker and R. Sarpeshkar, "Feedback analysis and design of RF power links for low-power bionic systems," IEEE Trans. Biomed. Circuits Syst., vol. 1, no. 1, pp. 28-38, 2007.

[49] J. Tan, S. Member, C. Heng, and Y. Lian, "Design of Ef fi cient Class-E Power Ampli fi ers for Short-Distance Communications," IEEE, vol. 59, no. 10, pp. 2210-2220, 2012.

[50] I. D. de Vries, J. H. van Nierop, and J. R. Greene, "Solid state class DE RF power source," IEEE Symp. Ind. Elcron., pp. 524-529, 1998.

[51] G. A. Kendir et al., "An optimal design methodology for inductive power link with Class-E amplifier," IEEE Trans. Circuits Syst. I Regul. Pap., vol. 52, no. 5, pp. 857-866, 2005.

[52] H. Sekiya, H. Koizumi, S. Mori, I. Sasase, J. Lu, and T. Yahagi, "FM/PWM Control Scheme in Class DE Inverter," IEEE Trans. Circuits Syst. I Regul. Pap., vol. 51, no. 7, pp. 1250-1260, 2004.

[53] S. M. Abbas, M. A. Hannan, and A. S. Salina, "Efficient Class-E Design for Inductive Powering Wireless Biotelemetry Applications Efficient Class-E Design for Inductive Powering Wireless Biotelemetry Applications," no. FEBRUARY 2012, 2016.

[54] T. Chan, C. Chen, and S. Member, "Transmission System," vol. 59, no. 8, pp. 1805-1814, 2012.

[55] M. Fu, S. Member, H. Yin, S. Member, and X. Zhu, "Analysis and Tracking of Optimal Load in Wireless Power Transfer Systems," pp. 1-12, 2014.

[56] F. H. Raab, "Idealized Operation of the Class E Tuned Power Amplifier," IEEE Trans. Circuits Syst., vol. 24, no. 12 , pp. 725-735, 1977.

[57] M. Ali and N. Hermawan, "Effective Power Amplifier of Wireless Power Transfer System for Consumer Electronics," Power Syst. Technol. (POWERCON), 2016 IEEE Int. Conf., pp. 0-4, 2016.

[58] M. J. Grebennikov, Andrei and Sokal, Nathan O. and Franco, Switchmode RF and Microwave Power Amplifiers, Second Edition, no. JULY 2012. 2012.

[59] N. O. S. ; A. D. Sokal, "Class E-A new class of high-efficiency tuned single-ended switching power amplifiers," IEEE J. Solid-State Circuits (Volume10, Issue 3 ), vol. Volume:10, no. Issue: 3, pp. 168-176.

[60] N. O. Sokal, “Class-E RF Power Amplifiers,” Notes, vol. 204, no. 204, pp. 9-20, 2001.

[61] A. Grebennikov, $R F$ and Microwave Power Amplifier Design. McGraw Hill Professional, 2004.

[62] Y. Kamito, K. Fukui, and H. Koizumi, "An Analysis of the Class-E Zero-Voltage-Switching Rectifier Using the Common-Grounded Multistep-Controlled Shunt Capacitor," IEEE Trans. Power Electron., vol. 29, no. 9, pp. 4807-4816, 2014.

[63] B. Andreycak, "Zero Voltage Switching Resonant Power Conversion," Unitrode U-138, pp. 329-355, 1999.

[64] Khmelnitsky EP., "Operation of Vacuum-Tube Generator on Detuned Resonant Circuit," Moskva: Svyazizdat, 1962.

[65] A. V Grebennikov, H. Jaeger, M. A. E. Operations, and L. T. Park, "HIGH-EFFICIENCY RF â€TM AND MICROWAVE POWER AMPLIFIERS," pp. 1627-1630, 2002.

[66] "ISM Bands." [Online]. Available: http://www.itu.int/dms pub/itu-s/oth/02/02/S02020000184501PDFE.PDF. [Accessed: 22-Apr-2016].

[67] P. Srimuang, N. Puangngernmak, and S. Chalermwisutkul, "13 . $56 \mathrm{MHz}$ Class E Power Amplifier with 94 . $6 \%$ Efficiency and 31 Watts Output Power for RF Heating Applications,” 2014.

[68] “MI.” [Online]. Available: http://www.mi.com/sg/pb10000/\#params. [Accessed: 22-May-2016]. 


\section{BIOGRAPHIES OF AUTHORS}

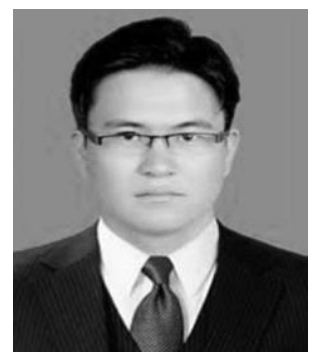

Muhammad Ali received the B.S. Electrical Engineering from University of Engineering and Technology, Khuzdar, Pakistan and M.S. Electrical Engineering from SEGi University, Kota Damansara, Malaysia in 2013 and 2017 respectively. He is currently pursuing Ph.D. degree in School of Information and Communication Engineering at Sungkyunkwan University, Suwon, Korea.

His research interests include power amplifier based wireless power transfer, power integrated circuits, CMOS RF transceiver and analogue integrated circuits.

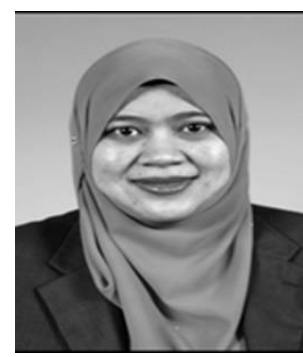

Nurulazlina Ramli received the B.Eng. degree in Electrical Engineering (Telecommunication) from the Universiti Teknologi Malaysia (UTM), Malaysia, in 2008, the M.Sc. degree in Telecommunication and Information Engineering, and the Ph.D. degree in Electrical Engineering with the Antenna Research Centre (ARC), from the Universiti Teknologi Mara (UiTM), Shah Alam, Malaysia, in 2011 and 2015, respectively.

Currently, she is a Lecturer with the Faculty of Engineering and the Built Environment (FoEBE), SEGi University, Kota Damansara, Malaysia since Sept. 2015. Between July 2008 and December 2009, she was a Postgraduate Assistant (Tutor) with the Faculty of Electrical Engineering, Universiti Teknologi Petronas (UTP), Sri Iskandar, Perak, Malaysia. She has authored several journal articles and conference papers. Her research interests include the areas of communication antenna design, electromagnetic radiation analysis, indoor/outdoor propagation modeling, radio astronomy antennas, and satellite antennas.

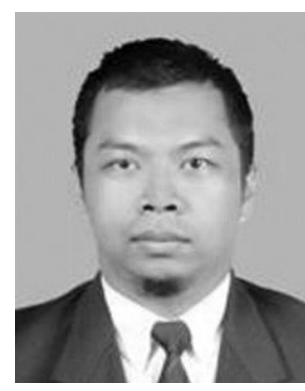

Hermawan Nugroho obtained his bachelor degree from Institut Teknologi Bandung (ITB, Indonesia) in 2005. He worked as a lighting Consultant before continuing his master degree in Universiti Teknologi Petronas (UTP), Malaysia. After finishing his M.Sc in 2007, he worked as Research Officer for several projects under UTP and Vitroc Technologies. In 2009, he persued is $\mathrm{PhD}$ in UTP while managing several projects in Centre for Intelligent Signal and Imaging Research (CISIR), UTP. He finished his PhD in 2014 and obtained his Professional Engineer from Indonesia in 2015. He joined SEGi University Kota Damansara from 2015 to Jan 2017. Dr. Nugroho joined the faculty of Engineering, Computing and Science, Swinburne University of Technology (SUTS) as senior lecturer on February 2017. Currently, he is a Senior Lecturer with the Department of Electrical and Electronic Engineering, Faculty of Engineering, University of Nottingham Malaysia since Feb. 2019.

His research interest includes image processing, medical image and signal analysis, statistical signal processing and pattern classification and machine learning. 